16,03

\title{
Атомная структура и энергия когезии изолированных кластеров SiC
}

\author{
(С) Л.И. Овсянникова \\ Институт проблем материаловедения им. И.Н. Францевича НАН Украины, \\ Киев, Украина \\ E-mail: avilon57@ukr.net
}

Поступила в Редакцию 19 октября 2019 г.

В окончательной редакции 19 октября 2019 г.

Принята к публикации 21 января 2020 г.

Проведены $a b$ initio расчеты атомной и электронной структуры, энергии когезии фуллереноподобных кластеров $\mathrm{Si}_{60} \mathrm{C}_{60}$. Впервые построена модель двухслойного кластера $\mathrm{Si}_{12} \mathrm{C}_{12} @ \mathrm{Si}_{48} \mathrm{C}_{48}$ со смешанными $s p^{2} / s p^{3}$-связями. Ab initio расчеты проводились в рамках теории функционала электронной плотности и гибридного функционала B3LYP. Проведена оценка стабильности и ширины энергетической щели кластеров в зависимости от их геометрии. Показано, что стабильность двухслойного кластера $\mathrm{Si}_{12} \mathrm{C}_{12} @ \mathrm{Si}_{48} \mathrm{C}_{48}$ превосходит стабильность остальных кластеров с тем же числом атомов, но уступает SiC-кластеру структуры сфалерита. В процессе релаксации у двухслойного кластера происходит смещение наружу поверхностного слоя.

Ключевые слова: карбидкремниевые материалы, атомные кластеры $\mathrm{SiC}$, компьютерное материаловеление.

DOI: 10.21883 /FTT.2020.06.49360.633

\section{1. Введение}

Карбид кремния обладает химической стабильностью, высокой стойкостью к повышенным температурам и ионизирующим излучениям. Полупроводниковый карбид кремния это базовый материал для приборов, предназначенных для работы в экстремальных условиях при высоких температурах и плотностях тока. Полупроводниковый $\mathrm{SiC}$ все шире используется в электронике и оптоэлектронике. Керамика на основе $\mathrm{SiC}$ обладает по сравнению с металлами более высокими механическими характеристиками, коррозионной стойкостью и устойчивостью к радиационным воздействиям. Композиты на основе углеродных волокон и карбида кремния обладают низким удельным весом, высокой устойчивостью к термическим перегрузкам, высокому сопротивлению к истиранию, что делает их лучшими кандидатами для изготовления систем торможения в автомобильной промышленности. В ракетной технике карбидкремниевые материалы используются в качестве рулевых заслонок реактивных двигателей, носовых защитных тепловых экранов. Для различных применений требуется как высокоплотная керамика без пор, так и пористые материалы с заданным размером пор и их распределением в объеме. Высокопористая керамика на основе $\mathrm{SiC}$ применяется для фильтрации расплавленных металлов и горячих газов, в теплообменных элементах для пористых горелок и др.

Карбид кремния существует в виде двух модификаций: с кубической кристаллической структурой $\beta$ - $\mathrm{SiC}$ (или $3 \mathrm{C}-\mathrm{SiC})$, стабильной до $2000^{\circ} \mathrm{C}$, а также с гексагональной и ромбоэдрической структурой $\alpha$-SiC стабильной при более высоких температурах $[1,2]$. В модификации $\alpha$-SiC объединены более 200 политипов. Основные структурные отличия политипов определяются только порядком чередования и периодом повторяемости слоев в направлении кристаллографической оси $Z$, типом примитивной элементарной ячейки, а также степенью гексагональности. Структура фаз карбида кремния подобна структурам с преимущественно ковалентным типом связей: алмазоподобным, кремниевым и другим фазам. У карбидкремниевых материалов со структурой, аналогичной алмазным фазам, структура может варьироваться в более широком диапазоне, чем у традиционных политипов $\mathrm{SiC}$ и их свойства могут существенно различаться. Карбидкремниевые материалы с такой структурой могут найти широкое применение в качестве конструкционных материалов, а также в электронных устройствах.

Получение новых карбидкремниевых фаз возможно из $\mathrm{SiC}$-кластеров. Возможная структура таких кластеров исследовалась в ряде работ $[3,4]$. Оптимизированная конфигурация, электронная структура и спектральные характеристики были рассчитаны в работе [5] для фуллереноподобных кластеров $\mathrm{Si}_{12} \mathrm{C}_{12}$ и ряда других широкозонных полупроводников состава $\mathrm{X}_{12} \mathrm{Y}_{12}$. Ряд кристаллообразующих кластеров карбида кремния $\mathrm{Si}_{n} \mathrm{C}_{n}$ и кристаллов на их основе был теоретически исследован в работе [6]. По результатам расчетов впервые было предложено 5 новых фаз, а также теоретически рассчитаны их дифрактограммы. В [7] предложена классификационная схема и модельный метод формирования фаз карбида кремния на основе наноструктур. Показано, что предложенные фазы существенно отличаются структурой кристаллических решеток, поэтому их свойства должны варьироваться значительно сильнее, чем свойства политипов карбида кремния.

Целью данной работы является исследование средствами компьютерного материаловедения структурных, электронных и когезионных свойств изолированных 
кластеров $\mathrm{Si}_{60} \mathrm{C}_{60}$ в качестве структурных единиц для проектирования новых карбидкремниевых фаз.

\section{2. Модель и метод исследования}

Для исследования первопринципными квантовохимическими методами электронных и когезионных свойств изолированных кластеров $\mathrm{SiC}$ в зависимости от их структуры мы предлагаем использовать три модели фуллереноподобных (ФП) кластеров и одну модель изолированного кластера структуры сфалерита. ФП-модели успешно применялись при исследовании пленок на основе $\mathrm{Zn}(\mathrm{Cd}) \mathrm{O}-$-пллава и взаимодействия собственных дефектов с примесью $\mathrm{Al}$ в решетке $\mathrm{ZnO}$ [8-10]. Мы ранее установили, что $\mathrm{A}^{\mathrm{II}} \mathrm{B}^{\mathrm{VI}}$ соединения проявляют тенденцию формировать фуллереноподобные структуры [5]. В таких структурах, энергия когезии меньше чем для основных твердотельных структур. Также, энергия когезии увеличивается с ростом числа атомов в кластере, таким образом большие кластеры устойчивее, чем более маленькие. Хотя нет полной ясности в наблюдаемой тенденции сокращения ширины запрещенной зоны с увеличением размера кластера, но значение энергии запрещенной зоны для кластеров зависит не только от размера кластера; на это могут повлиять другие факторы такие как геометрия $[11,12]$.

Для определения структурной зависимости энергии когезии кластеров $\mathrm{SiC}$, нами была проведена сравнительная оценка стабильности кластеров с одинаковым числом атомов, но разной геометрии: ФП-кластера $\mathrm{Si}_{60} \mathrm{C}_{60}$, координационного тетраэдра $\left(\mathrm{Si}_{12} \mathrm{C}_{12}\right) 5$, двухслойного кластера $\mathrm{Si}_{12} \mathrm{C}_{12} @ \mathrm{Si}_{48} \mathrm{C}_{48}$.

B $[13,14]$ было показано, что при построении моделей сферических кластеров можно использовать структурные фрагменты известных кристаллических модификаций исследуемых веществ. Например, фрагменты алмаза и лонсдейлита были использованы для построения модели частиц икосаэдрического наноалмаза, в которых локальное окружение атомов углерода практически не отличалось от того, что имеет место в алмазе, а в центре модели располагался фуллерен $\mathrm{C}_{20}$. Подход, изложенный в $[13,14]$ и примененный нами ранее в [15] мы использовали для построения модели двухслойного $\mathrm{Si}_{12} \mathrm{C}_{12} @ \mathrm{Si}_{48} \mathrm{C}_{48}$ кластера со смешанными $s p^{2} / s p^{3}$-связями (рис. 1).

ФП-кластер $\mathrm{Si}_{60} \mathrm{C}_{60}$ с $s p^{2}$-связями (рис. 2,a), где каждый атом $\mathrm{Si}$ окружен атомами С и наоборот, является структурным аналогом фуллерена $\mathrm{C}_{120}$. Координационный тетраэдр $\left(\mathrm{Si}_{12} \mathrm{C}_{12}\right) 5$ (рис $\left.2, b\right)$ состоит из пяти ФП $\mathrm{Si}_{12} \mathrm{C}_{12}$-Кластеров с $s p^{2}$-связями. Кластер $\mathrm{Si}_{12} \mathrm{C}_{12}$ симметрии $\mathrm{T}_{\mathrm{h}}$ образован 6 квадратами и 8 гексагонами, где каждый атом кремния имеет окружение из трех атомов углерода и наоборот. Этот кластер в силу его кубического типа симметрии может служить структурной единицей цеолитоподобных периодических структур [16]. Кластеры $\mathrm{Si}_{12} \mathrm{C}_{12}$ объединенны по гексагонам

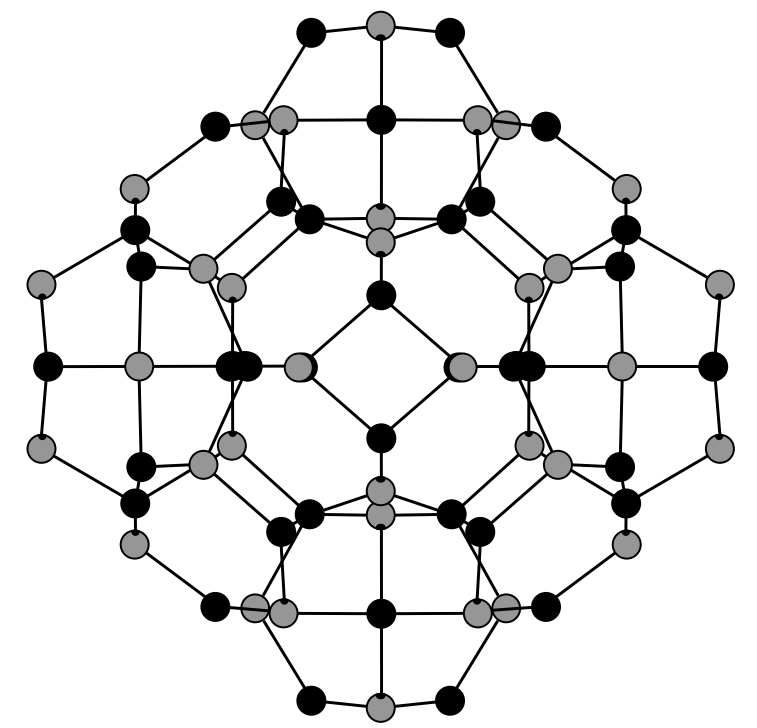

Рис. 1. Исходная модель $\mathrm{Si}_{12} \mathrm{C}_{12} @ \mathrm{Si}_{48} \mathrm{C}_{48}$ кластера со смешанными $s p^{2} / s p^{3}$-связями, где темные шарики $-\mathrm{Si}$, светлые шарики - $\mathrm{C}$.

$s p^{3}$-связями в структуру аналогичную алмазному тетраэдру, где вместо атомов расположены кластеры $\mathrm{Si}_{12} \mathrm{C}_{12}$. Двухслойный кластер $\mathrm{Si}_{12} \mathrm{C}_{12} @ \mathrm{Si}_{48} \mathrm{C}_{48}$ c $s p^{3}$-типом связи между слоями и $s p^{2}$-связями в наружном слое построен для исследования свойств кластера от его структуры, а также исследования поведения поверхностного слоя в процессе его релаксации.

Модель двухслойного $\quad \mathrm{Si}_{12} \mathrm{C}_{12} @ \mathrm{Si}_{48} \mathrm{C}_{48} \quad$ кластера (рис. 2,c) построена на основе ядра из кластера $\mathrm{Si}_{12} \mathrm{C}_{12}$ (слой $\mathrm{L}_{1}$ ). При построении наружного слоя $\mathrm{L}_{2}$ были использованы структурные фрагменты SiC-структуры сфалерита. Ядро декорировано структурными фрагментами таким образом, что каждый атом ядра является местом роста следующего сфалеритоподобного слоя. $\mathrm{B}$ полученной частице $\mathrm{c}$ двухслойной структурой $\mathrm{Si}_{12} \mathrm{C}_{12} @ \mathrm{Si}_{48} \mathrm{C}_{48}$-Кластера, из 120 атомов ее составляющих, 48 атомов объединены $s p^{3}$-связями, а 72 поверхностных атома $s p^{2}$-связями. Предполагается, что данная методика позволит построение модели частицы с многослойной структурой.

Модель изолированного $\mathrm{Si}_{43} \mathrm{C}_{32}$-кластера со структурой сфалерита построена путем вырезания сферического пятислойного кластера из твердотельной структуры $\mathrm{SiC}$. Для стабилизации кластера в процессе расчетов с поверхности были удалены все атомы, имеющие с кластером одну связь. В итоге получена структура с неравным числом атомов $\mathrm{Si}$ и С со смешанными $s p^{2} / s p^{3}$-связями на поверхности и $s p^{3}$-связями внутри кластера (рис. 3).

Оптимизированная геометрия, полная энергия, электронная структура, распределение электронной плотности кластеров, рассчитаны в рамках метода RHF и теории функционала электроннй плотности DFT с гибридним функционалом B3LYP и базисним набором 


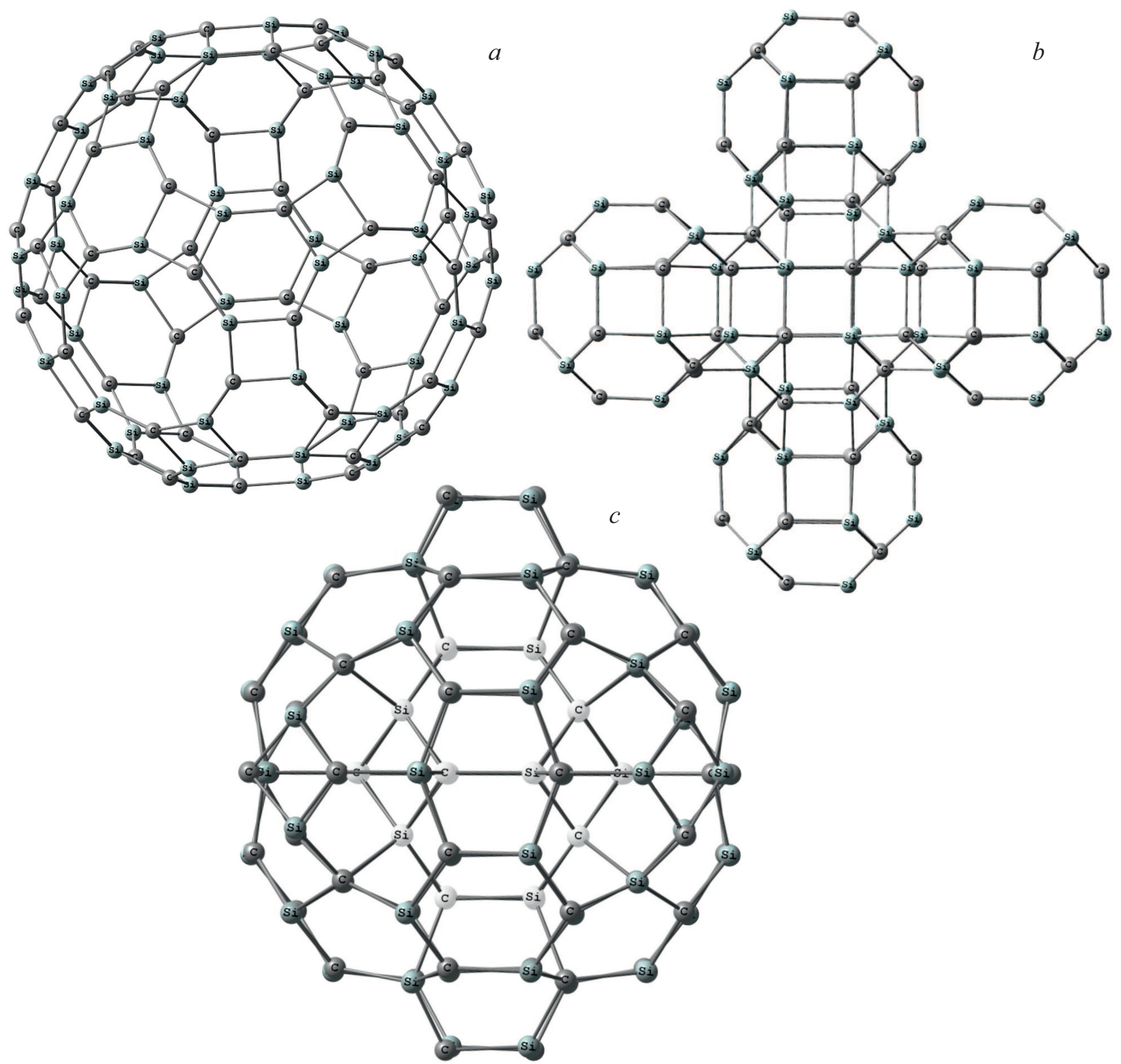

Рис. 2. Оптимизированные геометрии ФП-кластеров $\operatorname{Si}_{60} \mathrm{C}_{60}$ : ФП $\mathrm{Si}_{60} \mathrm{C}_{60}(a)$, координационный тетраэдр $\left(\mathrm{SiC}_{12}\right) 5(b)$, двухслойный $\mathrm{Si}_{12} \mathrm{C}_{12} @ \mathrm{Si}_{48} \mathrm{C}_{48}(c)$, где темные шарики - $\mathrm{Si}$, светлые шарики - C.

Энергетические и геометрические параметры кластеров $\mathrm{SiC}\left(\mathrm{E}_{c} /\right.$ pare-atom $\mathrm{Si}-\mathrm{C}$ - энергия когезии на пару атомов $\mathrm{Si}-\mathrm{C}, \mathrm{eV}$, $\mathrm{E}_{g}$ - ширина энергетической щели, $\mathrm{eV}$, длина связи - расстояние между центрами атомов $\mathrm{Si}-\mathrm{C}$ в шестичленных кольцах, $\mathrm{nm}$; $d_{\mathrm{L}_{1}-\mathrm{L}_{2}}-$ расстояние между слоями $\mathrm{L}_{1}$ и $\mathrm{L}_{2}$ по атомам $\mathrm{Si}$ и атомам $\mathrm{C}, \mathrm{nm}$ )

\begin{tabular}{l|c|c|c|c}
\hline Кластер & $\begin{array}{c}\mathrm{E}_{c} / \text { pare-atom } \mathrm{Si}-\mathrm{C}, \\
\mathrm{eV}\end{array}$ & $\begin{array}{c}\mathrm{E}_{g}, \\
\mathrm{eV}\end{array}$ & $\begin{array}{c}\text { Длина связи } \mathrm{Si}-\mathrm{C}, \\
\mathrm{nm}\end{array}$ & $\begin{array}{c}d_{\mathrm{L}_{1}-\mathrm{L}_{2},} \\
\mathrm{~nm}\end{array}$ \\
\hline $\mathrm{Si}_{60} \mathrm{C}_{60}$ & 33.668 & 2.152 & $0.177-0.179$ & - \\
\hline$\left(\mathrm{SiC}_{12}\right) 5$ & 33.527 & 2.054 & $0.193-0.197$ & - \\
\hline $\mathrm{Si}_{12} \mathrm{C}_{12} @ \mathrm{Si}_{48} \mathrm{C}_{48}$ & 33.844 & 1.717 & $1_{1} 0.195$ & $\mathrm{Si} 0.232$ \\
& & & $1_{2} 0.18-0.184$ & $\mathrm{C} 0.219$ \\
\hline $\mathrm{Si}_{43} \mathrm{C}_{32}$ & 34.390 & 0.713 & 0.187 &
\end{tabular}




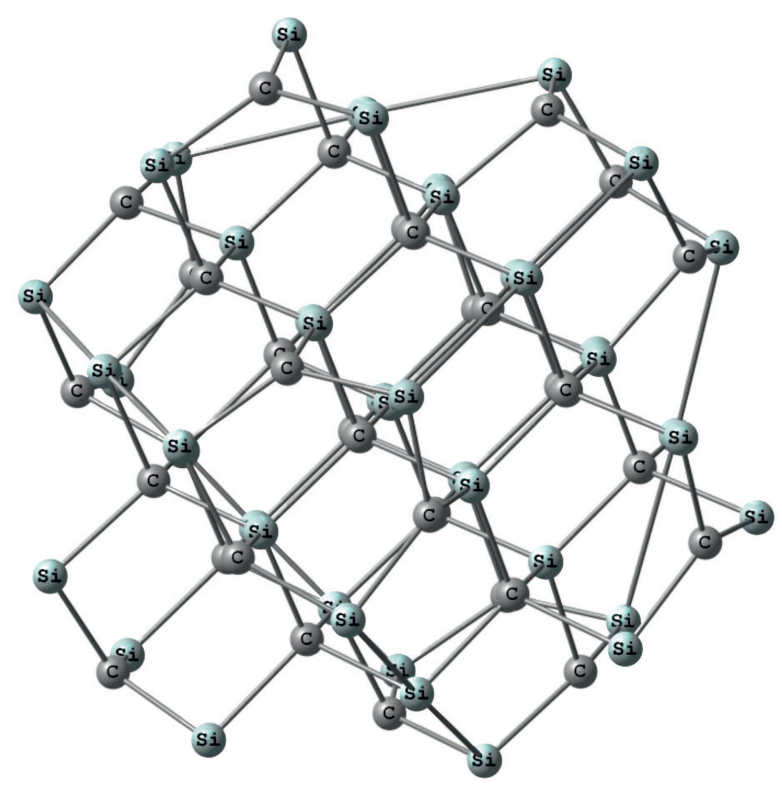

Рис. 3. Оптимизированная геометрия кластера структуры сфалерита $\mathrm{Si}_{43} \mathrm{C}_{32}$, где темные шарики $-\mathrm{Si}$, светлые шарики - C.

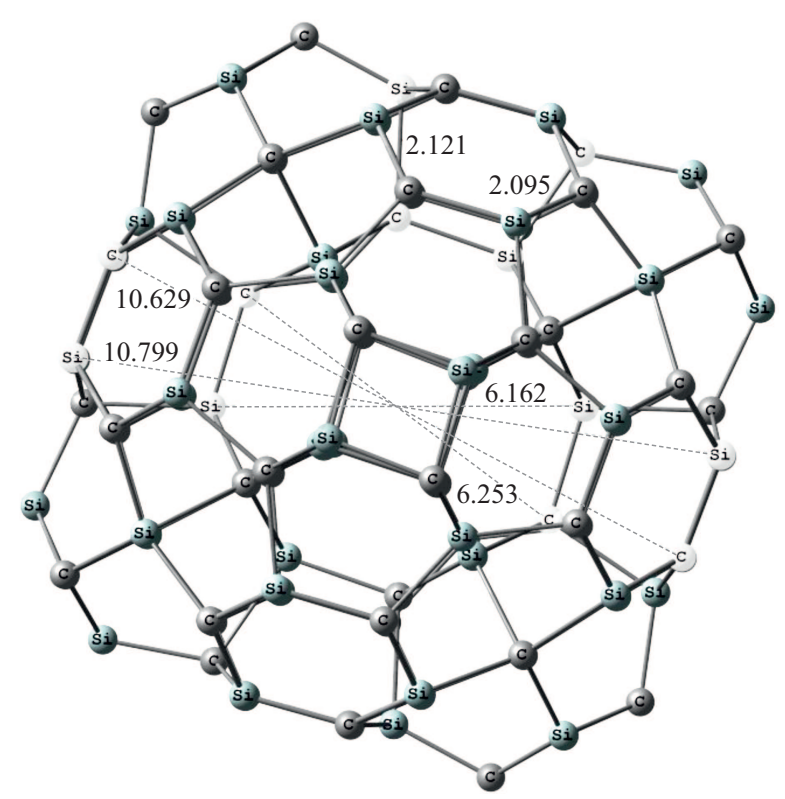

Рис. 4. Оптимизированная геометрия двухслойного кластера $\mathrm{Si}_{12} \mathrm{C}_{12} @ \mathrm{Si}_{48} \mathrm{C}_{48}$ со смешанным $s p^{2} / s p^{3}$-типом связи. Диаметр слоев $\mathrm{C} \mathrm{L}_{1}$ и $\mathrm{C}_{2}, \mathrm{Si} \mathrm{L}_{1}$ и $\mathrm{Si} \mathrm{L}_{2}$ использован для расчета расстояния между внутренним и наружным слоями. Размер между центрами атомов показан в $\AA$.

MINI [17]. Гибридный функционал с точным обменным взаимодействием, рассчитанным методом Хартри-Фока, обеспечивает алгоритм улучшения предсказания многих свойств кластеров, таких как энергия атомизации, длина химических связей, частоты колебаний. Энергия когезии на пару атомов рассчитывалась как полная энергия кластера за вычетом энергии удаленных в бесконечность составляющих его атомов без учета нулевых колебаний деленная на число атомных пар (для ФП-кластеров равное 60). Для кластера $\mathrm{Si}_{43} \mathrm{C}_{32}$ число атомных пар принято равным 37.5 вследствие неравного числа атомов $\mathrm{Si}$ и $\mathrm{C}$.

При выполнении расчетов были использованы: комплекс программ GAMESS'09 [18], программы визуализации расчетов ChemCraft и Molekel 5.4 [19].

\section{3. Обсуждение вычислительного эксперимента}

Результатами расчетов явились оптимизированная геометрия и электронная структура исследуемых объектов. Результаты расчета электронной структуры, энергия когезии в пересчете на атомную пару Si-C представлены в таблице. Вычисления показали, что наиболее стабильным оказался кластер $\mathrm{Si}_{43} \mathrm{C}_{32}$ структуры сфалерита, а среди ФП-кластеров двухслойный $\mathrm{Si}_{12} \mathrm{C}_{12} @ \mathrm{Si}_{48} \mathrm{C}_{48}$. Ширина энергетической щели между верхней заполненной и нижней незаполненной молекулярными орбиталями уменьшается с увеличением количества $s p^{3}$-связей в кластере: от ФП $\mathrm{Si}_{60} \mathrm{C}_{60^{-}}$до $\mathrm{Si}_{43} \mathrm{C}_{32}$-структурой сфалерита. Длина связи $\mathrm{Si}-\mathrm{C}$ в 6-членном кольце исследованных ФП-кластеров $0.193-0.197 \mathrm{~nm}$ корелирует с экспериментальными данными [20] и длиной связи $0.2009 \mathrm{~nm}$ в твердотельном $\mathrm{SiC}$ [21]. Длина связи в кластере $\mathrm{Si}_{43} \mathrm{C}_{32}$-стуктуры сфалерита $0.1869 \mathrm{~nm}$ корелирует данными расчета атомной структуры 3C-SiC-пленки [22] $0.18746 \mathrm{~nm}$.

Анализ длины связи и расстояния между поверхностным и внутренним слоями в двухслойном $\mathrm{Si}_{12} \mathrm{C}_{12} @ \mathrm{Si}_{48} \mathrm{C}_{48}$ представлен в таблице и на рис. 4. Для оптимизированной геометрии кластера $\mathrm{Si}_{12} \mathrm{C}_{12} @ \mathrm{Si}_{48} \mathrm{C}_{48}$ длина связи $\mathrm{Si}-\mathrm{C}$ равна $0.195 \mathrm{~nm}$, что корелирует с длиной связи $0.2009 \mathrm{~nm}$ в [22]. Расстояние между поверхностным и внутренним слоями составило для слоев кремния $\mathrm{SiL}_{1}$ и $\mathrm{Si}_{2} 0.232 \mathrm{~nm}$ и слоев углерода $\mathrm{CL}_{1}$ и $\mathrm{CL}_{2} 0.219 \mathrm{~nm}$. Длина связи $\mathrm{Si}-\mathrm{C}$ между слоями составляет $0.2095-0.212 \mathrm{~nm}$, что больше чем длина связи $\mathrm{Si}-\mathrm{C}$ внутри слоя.

Исследование расчета атомной структуры ФП двухслойного $\mathrm{Zn}_{12} \mathrm{Se}_{12} @ \mathrm{Zn}_{48} \mathrm{Se}_{48}$ кластера показало. что в процессе оптимизации расстояние между внутренним и наружным слоем увеличивается, изначальная гофрировка верхнего слоя уменьшается. Похожий эффект получен в результате первопринципных расчетов атомной и электронной структуры не реконструированной поверхности пленки $3 \mathrm{C}-\mathrm{SiC}$ со структурой сфалерита [22].

\section{4. Заключение}

Анализ исследования ФП-кластеров $\mathrm{Si}_{60} \mathrm{C}_{60}$ показал. что из исследованных кластеров наиболее стабилен и близок к твердотельному $\mathrm{SiC}$ двухслойный ФП-кластер $\mathrm{Si}_{12} \mathrm{C}_{12} @ \mathrm{Si}_{48} \mathrm{C}_{48}$, но уступает $\mathrm{SiC}$-кластеру структуры 
сфалерита. У кластера $\mathrm{Si}_{12} \mathrm{C}_{12} @ \mathrm{Si}_{48} \mathrm{C}_{48}$ длина связи $\mathrm{Si}-\mathrm{C}$ равна $0.195 \mathrm{~nm}$, что корелирует с длиной связи $0.2009 \mathrm{~nm}$ в [22]. В процессе оптимизации геометрии связи между атомами внутреннего и поверхностного слоя удлиняются, происходит смещение наружу поверхностного слоя.

ФП-кластеры $\mathrm{Si}_{n} \mathrm{C}_{n}$ кубических типов симметрии перспективны в качестве структурных единиц для построения новых карбидкремниевых структур. а также в качестве базовой модели для дальнейших исследований влияния примесей и собственных дефектов в структурах на основе $\mathrm{SiC}$.

\section{Конфликт интересов}

Авторы заявляют. что у них нет конфликта интересов.

\section{Список литературы}

[1] Г.Г. Гнесин. Карбидкремниевые материалы. Металлургия, М. (1977) 215 c.

[2] Г.С. Олейник, Н.В. Даниленко. Успехи химии 66, 615 (1997).

[3] M. Matsubara, C.J. Mossobrio. Chem. Phys. 122, 084304 (2005).

[4] M. Matsubara, C.J. Mossobrio. Phys. Chem. A 109, 4415 (2005).

[5] V.V. Pokropivny, L.I. Ovsyannikova. Phys. Solid State 49, 535 (2007).

[6] Л.И. Овсянникова, В.В. Покропивный, В.Л. Бекенев. ФТТ 51, 10, 2070 (2009).

[7] Е.А. Беленков, Э.Н. Агалямова, В.А. Грешняков. Наносистемы: физика, химия, математика 2, 3, 79 (2011).

[8] L. Ovsiannikova, V. Kartuzov, I. Shtepliuk, G. Lashkarev. Acta Phys. Polonica A 129, A-41 (2016).

[9] I. Shtepliuk, V. Khranovskyy, G. Lashkarev, V. Khomyak, V. Lazorenko, A. Ievtushenko, M. Syväjärvi, V. Jokubavicius, R. Yakimova. Solid-State Electron. 81, 72 (2013).

[10] L. Ovsiannikova, M. Dranchuk, G. Lashkarev, V. Kartuzov, M. Godlewski. Superlat. Microstruct. 107, 1 (2017).

[11] Z. Zhu, A. Chutia, R. Sahnoun, M. Koyama, H. Tsuboi, N. Hatakeyama, A. Endou, H. Takaba, M. Kubo, C.A. Del Carpio, A. Miyamoto. Jpn. J. Appl. Phys. 47, 2999 (2008).

[12] Amit Jain, Vijay Kumar, Yoshiyuki Kawazoe. Comput. Mater. Sci. 36, 258 (2006).

[13] В.Я. Шевченко, А.Е. Мадисон. Физика и химия стекла 32 , 1,118 (2006).

[14] А.Н. Еняшин, А.Л. Ивановский. ФТТ 49, 378 (2007).

[15] Л.И. Овсянникова. ФТТ 61, 786 (2019).

[16] V.V. Pokropivny, V.V. Skorokhod, G.S. Oleinik, A.V. Kurdyumov, T.S. Bartnitskaya, A.V. Pokropivny, A.G. Sisonyuk, D.V. Sheichenko. J. Solid State Chem. 154, 214 (2000).

[17] S. Huzinaga, J. Andzelm, M. Klobukowski, E. RadzioAndzelm, Y. Sakai, H. Tatewaki. Gaussian Basis Sets for Molecular Calculations. Elsevier. Amsterdam (1984).

[18] M.W. Schmidt, K.K. Baldridge, J.A. Boatz, S.T. Elbert, M.S. Gordon, J.H. Jensen, S. Koseki, N. Matsunaga, K.A. Nguyen, S.J. Su, T.L. Windus, M. Dupuis, J.A. Montgomery. J. Comput. Chem. 14, 1347 (1993).
[19] S. Portmann. Chimia 54, 766 (2000).

[20] Landolt-Bornstein / Ed.O. Madelung. New Series III. 22. Springer. Berlin (1987).

[21] Karl W. Boer. Handbook of the Physics of Thin-Film Solar Cells. Springer-Verlag Berlin (2013). P. 738.

[22] В.Л. Бекенев, С.М. Зубкова. ФТТ 60, 2033 (2018).

Редактор Т.Н. Василевская 